\title{
Stripe-to-bubble transition of magnetic domains at the spin reorientation of
} $(\mathrm{Fe} / \mathrm{Ni}) / \mathrm{Cu} / \mathrm{Ni} / \mathrm{Cu}(\mathbf{0 0 1})$

\author{
J. Wu, ${ }^{1}$ J. Choi,' C. Won, ${ }^{2}$ Y. Z. Wu, ${ }^{3}$ A. Schol], ${ }^{4}$ A. Dorar, ${ }^{4}$ Chanyong Hwang, ${ }^{5}$ and Z. Q. Qiu \\ 'Departunent of Physics, University of Califontia-Berkeley, Bekeley, Califormin 94720, USA

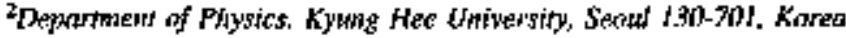 \\ ${ }^{3}$ Surface Phystes Laboratory (Natloutal Key Lubowarory, Futalt Universiny, Shanghai 200433, China \\ "Advanced Light Sowre, Lawrence Berkeley National Lahovafory. Berkeley. Calffornia 94720, USA

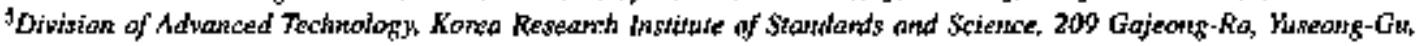 \\ Daejeorn 305.340, Korea
}

(Recejved 21 October 2008; revised manuscript received II Dexember 2008; pub] ished 22 Jaluaty 2009)

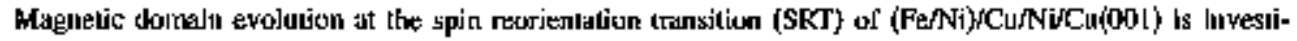
gated uxing photoemission electran microscopy. While the (FeN Ni) layer exhibits the SRT, the interlayer coupling of the perpendicularly inagnetized Ni loyer o the (Fe/Ni) layer serves as a virtusal perpendicular inagnetic field exerted on the (Fe/Ni) layer. We hind that the perpendicalar virnul nagnetic field breaks the up-dowm symmetry of the ( $\mathrm{Fe} / \mathrm{Ni}$ ) stripe domains to induce a net magnetizalion in the nomatal direction of the

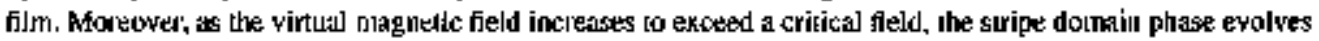
into a bubble dornsin phase. Although the crikical fietd depends on the Fe film thickness, we show thul the aret fraction of the minorily domain exhibits a nniversal yalue that determilues the stripe-to-bubthe phase Iransition.
\end{abstract}

DOI: 10.1103FhysReyB.79.014429

PACS number(s): $75.70 . \Omega \mathrm{k}$

\section{INTRODUCTION}

Spin reorientation transition (SRT) (Refs. I and 2) refers to the phenomenon of spin direclional change in magnetic materials due to the change in the so-called magnetic anisotropy. For example, in a magnetic thin film the competition between the perpendicular crystalline magnetic anisorropy and the in-plane magnelic shape anisotropy could switch the film magnetizalion frosn perpendicular to the in-plane directions of the film by changing the temperature or film thickness. Research on this subject has attuacled greal interest in the last decarles because of is connection to the magnetic ordering in 1wo-dimensional (2D) magnelic systems. ${ }^{34}$ It is shown that the apparent loss of the macroscopic magnetization withit a natrow gap of the temperature for film thickness) at the SRT is due to the formation of magnetic stripe phase. ${ }^{3}$ The stripe phase was also shown in experiment to exhibit unique dynamic properties. ${ }^{6,7}$ The difficulcy of applyung a magnetic field in an clectron microscope was also circumvented rocently by doing element-specific domain imaging in a magnetic sandwich where the magnetic interlayer coupling serves as a virtual magnetic fietd. ${ }^{8}$ In particulat, the improvement of the sample fabrication quality greatly enhances the domain inaging quality, ${ }^{9,10}$ making it possible to perform a quantitative analysis on the stripe domain width. ${ }^{R}$ These advances in experiment enable a deeper probe of some nechanisms that govem the magnetic phases at the SRT. For example, it is shown that the exponential decay of the stripe width toward the SRT point is a inauifest of a crossover finwn the anisotropy to the dipolar length seales and that a paramagnetic gap develops at the SRT point. ${ }^{.1,12}$ Recently research on this subject has been focused on the sefrch of new magnetic domsin phases at the SRT under different conditions. ${ }^{13,14}$ Because of the long-range chatacter of the dipolar istcraction, it is usually difficult for theory to predict the ground state of the magnetic phase. Thus oompuler simu-
Jation and special analylical solutions are usually employed to compare the energy of the stripe domain phase with the energy of other domain phases. ${ }^{15-17}$ In experiment, a recest ohseryation shows that after magnetizing a film with a mag. netic freld slightly tilling away from the film in-plane dirextion, the magnetic stripe phase of the film changes into a bubble domain phase. 18 This observation suggesis that there could exist olher dornain phases in competition with the stripe domain phase al the SRT, and the ground state of a $2 \mathrm{D}$ magnelic systern could be swiched Irom the stripe phase to the bubble phase within a magixtic ficld. In this paper, we report a studly of (Fe/Ni)/Cu/Ni(20 ML)/Cu(001) system in which the interlayer coupling between the perpendicular magnelized $20 \mathrm{MI}$. Ni tilm and the (Fi/Ni) film serves as a virtual perpendicular megnelic field applied to the (Fe/Ni) film which undergoes the SRT. By doing clement-specific magnetic dornain imasing using pholoemission election microscopy (PEEM), we investigated the (FefNi) stripe domain phase wilhis a perpendicular magnelic field. We find a phase transition from the stripe phase to the bubble phase as the viltual magnelic field exceeds a critical field. Furhemone, we reveal that this slripe-to-bubble phase transition is determined by a uriversal value of the minorily domais area frattion.

\section{RXPHRIMENT}

A 10-mm-diameter Cu(00I) single-crysial substrate was mechanically polisted with $0.25 \mu \mathrm{m}$ diamond past finish and clectropolished as previously reported. The Cu substrate was cleaned in an ultrahigh vacuum (UHV) system with a base pressure of $2 \times 10^{-10}$ Torr by cycles of Ar ion spulter. ing at $\mathrm{J}-5 \mathrm{keV}$ and armealing at $\sim 6000^{\circ} \mathrm{C}$ urtil sharp low enelgy electron diffraction (LEED) spols are observed. The sample of $[\mathrm{Fe} / \mathrm{Ni}(5 \mathrm{ML})] \mathrm{Cu} \mathrm{Ni}(20 \mathrm{ML})$ was grown epitaxially anto the $\mathrm{Cu}(001)$ substrate by evaporating $\mathrm{Fe}, \mathrm{Ni}$, and 
(a)

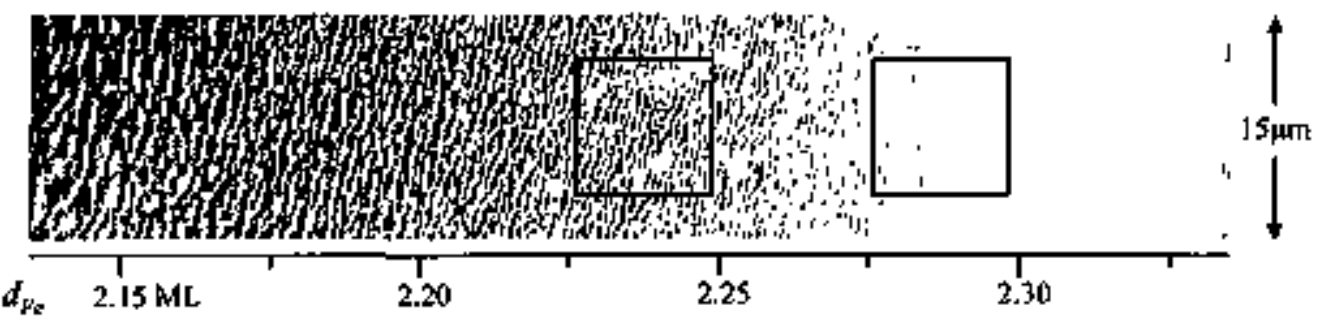

(b)

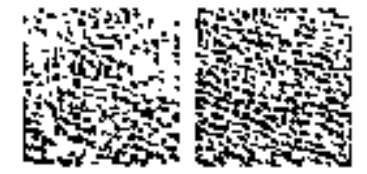

$d_{\mathrm{Or}} \quad 6,4 \mathrm{ML}$

6.3
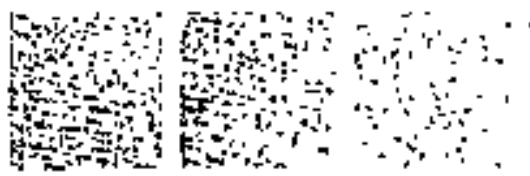

6.2

6.1

6.0

5.9

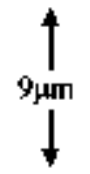

(c)
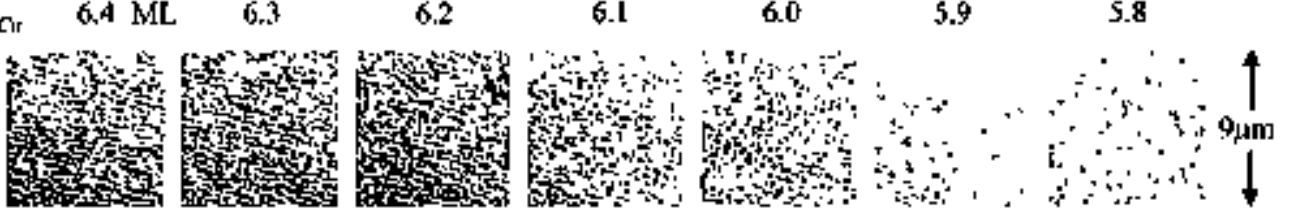

FIG. 1. (a) PEEM image of the Fe magnetc domains in Fo/Ni(5 ML)/Cu(6.40 ML)/Ni(20 ML)/Cu(00I). $d_{C_{0}}=6.40 \mathrm{ML}$ carresponds to

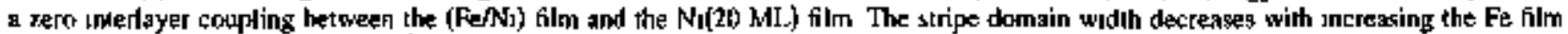

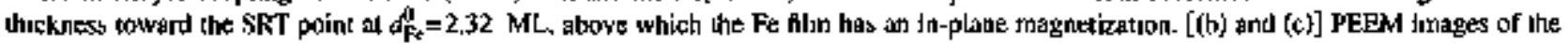

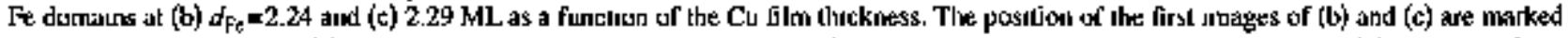

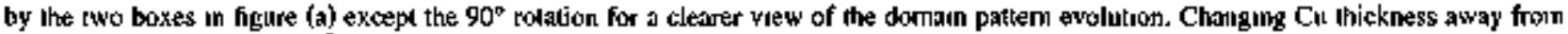

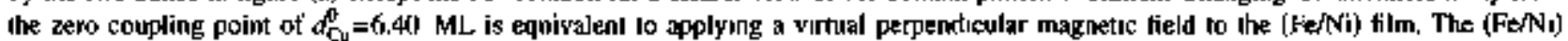
magnetic stripe phase evolves into a bubtble phuse before beng saturaled.

Co from thermal caucibles al an craporation rate of -I $\AA / \mathrm{min}$. The Fe $(0-5 \mathrm{ML})$ and $\mathrm{Cu}(0-15 \mathrm{ML})$ hims were grown into cross wedges over $2 \mathrm{~mm}$ lenglh along two orthogonal dinactions for the purpose of controlling their thicknesses independently.9 The wedge is formed by moving the subsirate behind a knife-cdge shutter during the growth with the wedge slope derived from the moving spetd and the evaporation rate. The sample was covered with a $10 \mathrm{ML}$. Cu proteclive layer before being transferred into the PEEM thamber at beamline 7.3.1.1 at the Advanced Light Sousce. The x-ray beam was circularly polarized and incident at an angle of $60^{\circ}$ to the surlace-normal direction. The magnetic domain images were obtained by taking the ratio of $f_{3}$ and $L_{2}$ edges utilizing the effect of $x$-ray magnetic circular dichroism (XMCD). Al] ineusurements wete made al room temperature.

The [F $: \mathrm{Ni}(5 \mathrm{ML})]$ bilayer betaves as a single ferromagnclic film because of the stıong direct fenomagnetic coupling belween the $\mathrm{Fe}$ and $\mathrm{Ni}$ magnetizations as previously reponed. ${ }^{8.9}$ The purpose of using a $5 \mathrm{ML} \mathrm{Ni}$ film is to shifi the SRT thickness of the $\mathrm{Fe} / \mathrm{Ni}$ into the ferromagnelic phase. of $\mathrm{fec} F \mathrm{fo}$ that the eomplicated forromagnetic-10antiferromagnetic Isansition of the foc Fe at $\sim 4 \mathrm{ML} \mathrm{Fe}$ is outside the SRT region of the Fe/Ni(5 ML). ${ }^{8}$ In this paper, we show only Fe PEEM images to represent the (Fe/Ni) magnetic domains. It was stown that the interlayel coupling in a magnelic-coupled sandwich serves as a vì tual magnetic field. ${ }^{3.19}$. Then since $20 \mathrm{ML}$. $\mathrm{Ni}$ on $\mathrm{Cu}(00 \mathrm{O})$ has a perpendicular magnetization, ${ }^{20}$ the SRT of the (Fe/Ni] Jayer in the [Fef $\mathrm{Ni}(5 \mathrm{ML})] / \mathrm{Cu} / \mathrm{Ni}(20 \mathrm{ML})$ system is equivalent to the SRT of a (ForNi) flin within a perpendicular magnotic ficld whose sucngth varics with the intcrlayer Cu thickness. At the PEEM beamline, prior to the PEEM measurement, the sample was magnetized in a ] kOe magnelic tield normal to the film surface to wipe out the magnetic domeans of the 20 ML Ni tilm, ensuring a uniform exchange coupling between the Ni and the (Fo/Ni) films.

\section{RESUILT AND DISCUSSION}

Figure 1 shows PEEM images of [ $\mathrm{Fe} / \mathrm{Ni}(5 \mathrm{ML})] \mathrm{Cu} / \mathrm{Ni}(20$ $\mathrm{ML}, \mathrm{Nu}(00 \mathrm{O})$ at $6.4 \mathrm{ML} \mathrm{Cu}$ where the interlayer coupling between the (FerNi) and the Ni layers is zero. Then the Fe magnelic images should represent the (FerNi) naguelic domains within a zelo external magnetic ficld. Below $d_{\mathrm{Fe}}^{0}=2.32 \mathrm{ML}$, the (Fe/Nu) film exhibits a clear stripe domain phase with the stripe width decreasing rapiclly with increasing the fie hitm thickltess. Above $2.32 \mathrm{ML}$, of the Fe film thickness, the (Fe/Ni) film possesses imegular magnetic domains. After rokating the sample around its surface-nomal direction by $90^{\circ}$, the domain contrast remains unchanged below $2.32 \mathrm{ML}$ of $\mathrm{Fe}$ but changes above $2.32 \mathrm{ML}$ of $\mathrm{Fe}$, showing that the ( $\mathrm{Fe} / \mathrm{Ni})$ magnetization is perpendicular to the film plane below $2.32 \mathrm{ML}$ of $\mathrm{Fe}\left(d_{\mathrm{Fe}}<2.32 \mathrm{ML}\right)$ and parallel to the film plane above 2.32 ML of Fe $\left(d_{\mathrm{Fe}}>2.32 \mathrm{ML}\right)$. Therefoic, we identify $d_{\mathrm{Fv}}^{0}=2.32 \mathrm{ML}$ to be the (FerNi) SRT point. The domain phase of the out-of-plane Fe magnelization will be the focus for the rest of this paper. Another observation from Fig. 1(a) is that the up (white) and down (dark) magnetic shipes have equal width, which is expected because the up.dowis symmesry should not be broken in the absence of ant extemal magnetic field." Recalling 
that the interlayer coupling between the (FerNi) and the 20 $\mathrm{MI}, \mathrm{Ni}$ layers oscillates with the Cu spacer layer thickness, ${ }^{21}$ the $d_{C_{0}}^{0}=6.40 \mathrm{ML}$ actually defines the boundary between the antiferrmagnetic interlayer coupling ( $d_{\mathrm{Cu}_{\mathrm{O}}}<6.40 \mathrm{ML}$ ) and the ferromagnetic coupling $\left(d_{\mathrm{Cu}}>6.40 \mathrm{ML}\right)$ regions. ${ }^{223}$ Thus the evolution of the stripe phase in the vicinity of $d_{C}=6.40 \mathrm{ML}$ represents the stripe phase evolution as a furction of a pecpendicular magnetic field applied to the (Fiei $N i)$ film.

We find that inereasing/decreasing the Cu thickness away from $d_{\mathrm{C}}^{0}=6.40 \mathrm{ML}$ results in the same domain cyolution except for a neversal of the white and dark domains. This is expected because ferromagnetic and anbiferromagnetic coupalings correspond to applying a perpendicular magnetic [etel to the (FerNi) film in the direction parallel and anizatallel to the 20 ML Ni magnetization, respectively, and thus should resuli in the same domain evolution after a reversal of the up-down disection (c.j., $H \rightarrow-H$ ). Because of the abowe facl and thal synchrotron beam time is limited, we only focus on one side of the Cu thickness away from the zero coupling point of $d_{C}=6.40 \mathrm{ML}$ to obtain high-quality domain images. In this paper, we will focus on the $d_{\mathrm{Co}}<6.40 \mathrm{ML}$ re gion where we oplimized the [PEM operation condition to obtain a gooul spatial resolution of the domain images. Figures L(b) and l(c) show a series of Fe domain images as a function of the Cu film thickness for two representative stripe dormains at $d_{\mathrm{F}_{\mathrm{t}}}=2.24$ and $2.29 \mathrm{ML}$, respectively [the arcas boxed in Fig. I(a)]. As the Cu thickness varies away from the zero coupling point or $d_{\mathrm{Cu}}^{0}=6.40 \mathrm{ML}$, the interlayer coupling strength increases (or the virtual magnetic field strength increases). We find that the inajourity (white) domain area expands at the cost of shrinking the minority (dark) domatn area, i.s, a net magnetization of the (FofNi) film, which is proportional to the area difference between the majority and minority domains that increases with the interlayer coupling strength. This is expected because a perpendicular magnetic field, which is simulated here by the interlayer coupling, should break the up-down domain symmetry to induce a net perpendicular mngnetization. The interesting obseryation of the PFEM images is that as the magnetizations increases with the interlayer coupling, the stripe domain phase also evolves in a manner where the minority (dark) stripes break al a point to develop bubble domain phasc $\left[d_{\mathrm{Cu}}<6.1 \mathrm{ML}\right.$ for Fig. $\mathrm{l}(\mathrm{b})$ and $d_{\mathrm{C}}<6.0 \mathrm{ML}$ for Fig. 1(c)]. Despite the ditTerence of the cul thickness where the bubble domain phase appears, measurentent at oher Fe thicknesses confinms the fact that the suripe phase evolves into the bubble phuse above a critical value of the inteslayer coupling strength (or equivalently speaking, above a critical value of the perpendicular magnetic field). Another interesting obseryation is that the majority (white) domain width and ared increase with the virtual perpendicular magnaclic fietd, but the width of the mincrily (black) Jomains changes very titlle regardless if $i$ is in the stripe phase or in the bubble phase.

To better undersiand the stripe-lo-bubble phase transilion, we perlomod the following quantitotive malysis of the PEEM images in Figs. ](b) and l(c). First, we antlyzed the dependence of the perpendicular magnetization ( $M$ ) of the (Fe/Ni) film on the perpendicular magnetic field $(H)$. Simce the magnetization is lincarly proportiona] to the area differ.

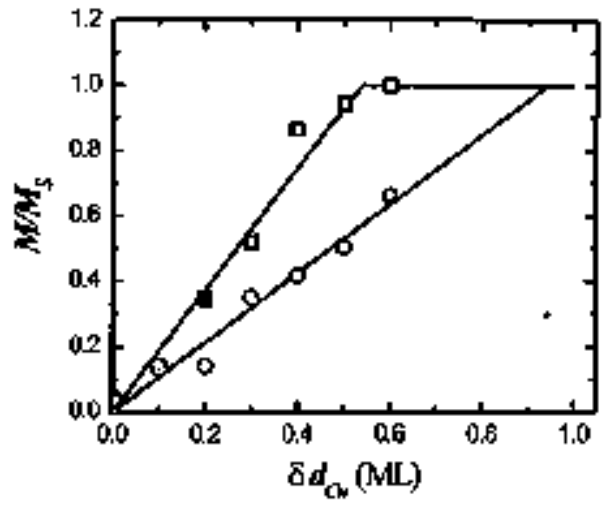

PIG. 2. (Color online) The normalized magnetization $M / M_{s}$ determined from PEEM images as a function of $\delta d_{\mathrm{Cr}}=\left|d_{\mathrm{C}_{\mathbf{a}}}-d_{\mathrm{Cu}}^{\mathrm{du}}\right|$ which simulales the stresgth of the perpendicular virtual magnelic

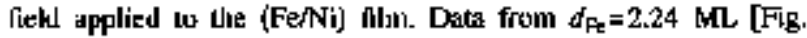
r(b)] are nopresented by square symbols; data from $d_{\mathrm{iz}}=2.29 \mathrm{ML}$ [Fig. I(c)] are represented by circular symbols. Solid symbols represent the smipe phase and open symbols represent the bubble phase. The solid lintes are guides for ine eyes.

ence of the majotily and minority domains, it is obvious that the nomalized magnetization $M / M_{5}$, where $M_{5}$ is the soluration magnetization, is determined by the area fraction (f) of the minority doinains in the form of $M / M_{S}=1-2 f$. Thus we determinc the (Fo/Ni) nonmalized magnctization $M / M_{3}$ by calculating the minorily domain area fraction of the PEEM images al dillerent Cu thicknesses. Second, we assume that the interlayer coupling strengih, which simulates the perpendictur thagnelic [reld, in the vicinity of zero coupling is linearly proportional to the Cu thickncss differesce away from the zero coupling point $\left[H \times A_{\mathrm{Cu}}=\left|d_{\mathrm{Cu}}-d_{\mathrm{Cu}}\right|\right]$ ] Therefore Fig. 2 aclually represents the result of the normalized magnetization $M / M_{S}$ versus a perpendicular magnetic field for the domain images of Figs. I(b) and I(c). In both cases, the $M / M_{3}$ increases monotonically with $\delta d_{\mathrm{Cu}}$ toward ils saluration. The ditlerent slopes of the $M / M_{S}$ vs $\& d_{C u}$ reflect the fact of diflerenl saturation magnetic field at the two Fe film thicknesses. This result is nor surprising because a film closer to the SRT point should have a weaker over'all perpendicular magnetic aslisotropy thus a greatcr saturalion magnetic ficld in the perpendicular direction. The stripe-tobubble phase transition, however, does not generale any abnorinal behavior of the $M / M_{S} \alpha d_{C u}$ curve, showing that the domain paltem change does not produce any cbvious disconlinuity in the macroscopic magnetization. Another result of Figs. I and 2 is that the stript-to-bubte phase uansition occurs at different $\delta t_{\mathrm{Cu}}$ for the two Fe film Ihicknesses, indicating that this stripe-10-bubble donain transition depends on both the perpendicular magnetic field and the inugnetic anisolropy.

The result of Figs. 1 and 2 shows that although the macroscopic magnetization does not show any anomaly in response to a perpendicular magnetic tiekd wilhin the SRT region, the magnetization process is accompanied by two types of dislinguishoble magnclic domain phases. (I) At low field, $M / M_{S}$ increases with $H$ in a manner of relaining the stripe domain phose. (2) Above a crilical field, the minority stripes 


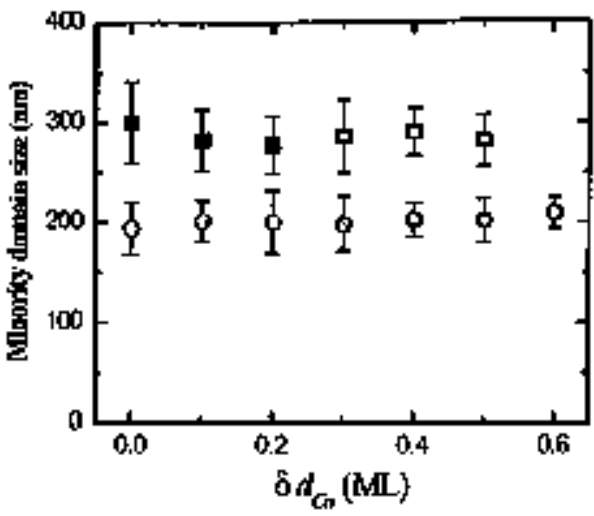

FIO. 3. (Color online) The minority domain size as a function of

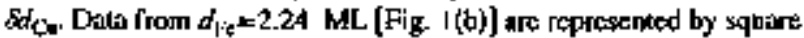

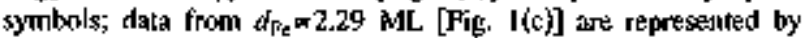
circuler symbols. Solid symbols represent the siripe phase and open syinbols represten! the bubble phase.

slart to break to eyolve into a bubble domain phase. Noticing that the $M / M_{S}$ is proportional to the area difierence between the majority and minorily domains, we should focus ouc attention on the domain size change during the magnetization process. As shown in Figs l(b) and $1(\mathrm{c})$, the majority (whire) domein area increases with $\boldsymbol{H}$ but its domain size becomes ill defined especially after the majority stripes merge together. On the other hand, the minority (dark) domain size can be reliably determined from the PEEM images so thal we delemine and plol the minority domain size as a function of $\delta d_{0 u}$ in Fig. 3. Here the minorily domain size is defined as the stripe width in the stripe phase or the bubble diameler in the bubb]e phase. It is clear trom Fig. 3 that the minority domain sjze remains roughly a constant with increasing the $a f_{\mathrm{Cu}}$ despite the increased $M / M_{S}$ and the stripeto-bubble phase transition. Combining the information from Figs. 2 and 3 , we summarize the microscopic scenario of the

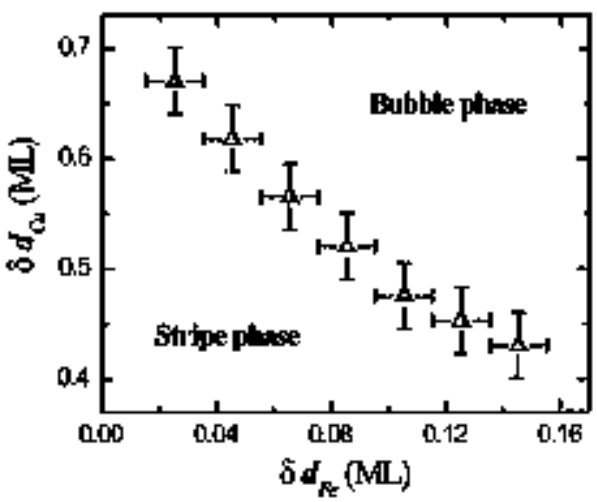

FIG. 4. (Color online) Phase diagram of the magnetic domains in the $\delta d_{\mathrm{Fe}}-d_{\mathrm{Cu}}$ plant. Here $d d_{\mathrm{Fc}}=\left|d_{\mathrm{Fr}}-d_{\mathrm{Fe}}\right|_{1}$ where to $=2,32 \mathrm{ML}$ is the \$RT point, is proportional to the perpendiculat

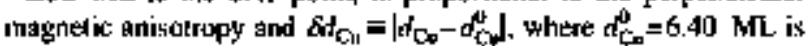
Uhe zero interlayes coupliug point, ts proportional to the yistual per. pendicular megnetic field applied to the (Fe/Ni) SRT filmb. The boundary belween the stripe and bubble plases is marked by the |riangle symboil.

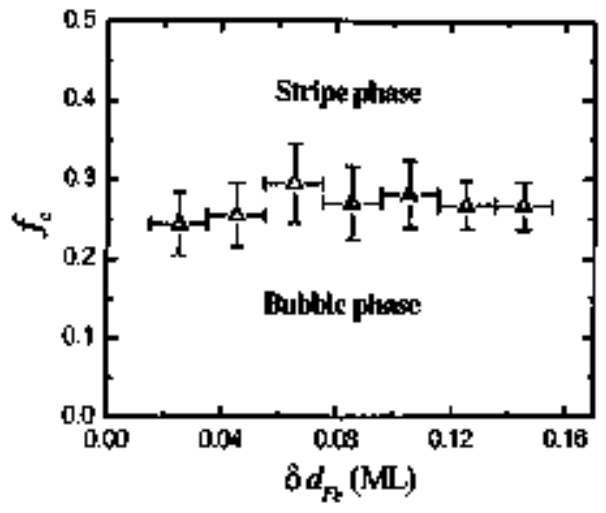

F[G. 5. (Color online) Critical area fraction $f_{x}$ as a function of $\delta t_{\mathrm{Pe}}$. The independence of $f_{\mathrm{r}}$, on $\delta d_{\mathrm{Fa}}$ shows that it is the area froction $f$ that desermibes the siripe-to-bubble phase transition.

magnetization process as the following. At Iow magnetic field, the majority stripe width expands while the minority stripe width remeins unchanged. Above a critical field, the mitiority stripes break into bubbles to further shrink the minority domain area while keeping the bubble domain size unchanged. Il should be pointed out that the unchanged mi. nority Lomain size shows thal the magnetization of the filst must take place by annihilating the minority stripes al low ficld. Unfortunately we cannot reveal this process because it tequires the inaging of the same area within a magnetic field.

The appearance of the bubble domain phase in the magnctization process nets mote analysis, especially on why the bubble domain phase appears above a critical magnetic tield. Figures I(b) and I(c) show that the critical magnetic field (or $\delta d_{c w}$ ), where the bubble domain phase appears, depends on the perpendicular magnetic anisotropy (or $d d_{\mathrm{Fe}}=\left|d_{\mathrm{F}_{t}}-d_{\mathrm{Fc}}^{0}\right|$, where $d_{\mathrm{F}_{0}}^{0}=2.32 \mathrm{ML}$ is the SRT point). We identified the stripe-t0-bubble phase-Iransition position from the PEEM images and plot the stripe/bubble phase boundary in the $\delta d_{\mathrm{fe}}-\delta d_{\mathrm{C}}$ plane (Fig. 4). Figute 4 displays a clear dependence of the critical field (or $\delta d_{C u}$ ) on the magnetic anisotropy (or $\delta d_{\mathrm{Fe}}$ ), showing that neither the critical field nor the magnetic anisolropy alone determines the stripe-tobulible phase transition. In an efforl to find a universal behavior underlying the stripe-10-bubble phase transition, we determined the dyea traction $f_{c}$ of the minority domains al the siripe-to-bubble transilion boundary and plot the fesult in the $f-\& d_{10}$ plane (Fig, 5). In this plane, the critical arca fracLion $f_{c}$ separates the stripe and the bubble phases for each $\delta d_{\mathrm{Ft}}$. Then we find an important tesult from Fig. 5 that this critical areat fraction $f_{C}$ is inderpendent of the $\delta d_{\mathrm{Fe}}$ showing that it is the arca fraction $f$ that atetermines the stripe-tobubble phase transition. Taking into account the thickness vatiation, we can draw a conclusion that the ground state of the (Fe/Ni) domains is in the stripe phase for $f<0.2$ and in the bubble phase for $f>0.3$ with $0.2<f<0.3$ being the tran. sition region between these two phases.

Al the end, we discuss some existing theories relating to the stripe phase within a perpendicular magnetic field. The appearance of the magretic domairs in the SRT region is a 
resull of the compelition anong the long-range dipole interaction, the shoit-range magnetic exchange interaction, and the on-site magnelic anisotropy. Specifically, the exponential decrease in the strije width toward a minimum value at the SRT point is a result of an anisotropy-to-dipole length scale crossover-" For a 2D Heisenbery system consisting of a uniaxial magnetic anisouropy, the stripe domain cyolution as a function or a perpendicular magnetic fiejd has been adiressed theoretically in the region where the slripe width is much greater than the minimum domain width (or where the anisotropy length governs the magnetic onder). 'The resuli shows that the increased magnetizatiun in response to a per'pendiculat magnetic field is realized by expanding the majority stripe width. ${ }^{24}$ However, the theory also prodicts that the minorily stripe width should remain a finite value even as the mactoscopic magnelization approaches its saturation. Althougl it is not justified to apply the above theory directly lo the regime close to the SRT point (Ihe case in our experimenl or the regime where the dipole length govems the magnelic ordir), ${ }^{\text {" }}$ the unchanged minority domain width in our experimental observation is to a certain degree capilured by the above aleory. This result was also evidenced in previous experiments, although the relative poor sample quality produces large fluctuations in the minority domain width. ${ }^{6,10} \mathrm{On}$ the other hand, the appearance or the hubble domain phase reported in the present paper is certainly nol included in preyious theories and experiments.

Another simplificd model considers only the domain-walt entergy and the dipole interaction energy. ${ }^{25}$ Since hoth energy Items kepend on specific alomain pattems, the model compared the total energy of stripe phase and bubble phase within a perpendicular magnetic field. By changing the tomain patlem from stripe phase into bubblc plase, the inereased domain-wall energy due to the incrcased domainwall length is accompanied by a decrease in the dipole interaction energy. Thus the final dnimain stale will depend on the competition betwoen the above lwo tems. By a numerical simulation, the model slows that although the magnetization (or area fraction $f$ depends litle on the domain pattems, the stript- and bubble-phase cnergics do cross as a function of the minority area fraction, kading to a lower encrgy for stripe phase for $f>0.28$ and a lower energy for bubble phase for $f<0.28$. This resull agrees well will our experimental observation. Reference 25 further predicts that in the viciuily of $f_{\mathrm{c}}=0.28$, the system should process a phase separation inlo a superposition of kiripe and bubble donain phases in a narrow region around $f_{1}$. This also agres with our observation that the stripe and bubble domains coexist in the vicinity of the stripe-to-bubble phase-lransition boundary. Although this simplified mode] cxplains the apparance of the bubble domsin phase within a perpendicular magnetic freld, the model ignores the magnelic anisotropy term. We wish thal fulure theoretical study could be carried ond 10 directly address our experimental obseryation.

\section{SUMMARY}

In summary, we studied the domsin evolution of ( $\mathrm{Fe} / \mathrm{Ni}$ ) filun at the SRT in (FerNi)/Cu/Ni/Cu(O0I) where the interlayer coupling simulates a virtual perpendlicular magnelic field applied to the (Fer Ni) film. We find that as the masnetic lield increases, the (FoNi) magnerization initially incretses by incleasing the majority domain arca while kecping the minerity stripe width unchenged, and then above a critical magnetic field the minority stripes brak to evolve into a bulbble domain phase. We further show that although the critical field depends on the magnetic anisoliopy, a universal value of the minority domain arca fraction $\left(f_{C}-0.2-0.3\right)$ determines the stripe-to-bubble phese transition.

\section{ACKNOWLEDGMENTS}

This work was supported by National Science Foundation under Gremt No. DMR-0503305, U.S. Department of Energy under Grant No. DE-ACO2-05CHI1231, National Nalural Science Foundalion of Chilla 973-Project under Grant No. 2006CB921300, ICQS Chincse Acadcmy of Sciences, and KICOS throygh Global Research Laboratory project.
'D. P. Pappas, K. P. KḦmper, and H. Hopster, Phyx. Rev. Lell. 64, 3179 (1990).

${ }^{2}$ Z. Q. Qiu, J. Pearson, and S. D. Bader, Phys. Rey. Lett. 70, 1006 (1993).

${ }^{3}$ N. D. Mermin and H. Wagres, Phys. Rev. Lett. 17, 1133 (1966).

${ }^{4}$ Myrum Bauder aly D. L. Mills, Phys. Rey. B 3B, I2015 (1988).

${ }^{5}$ R. Allestsyach and A. Bischof, Phys. Rev. Lent. 69, 3385 (1992):

"O. Portmant, A. Vaterlaus, and D. Pescia, Nature (I ondon) 422, 701 (2003).

${ }^{7}$ O. Portınatul, A. Vaterlaus, und D. Pescia, Phys. Rev. Let. 96, 047212 (2006).

${ }^{8}$ Y. Z. Wi, C. Won, A. Scholl, A. Daran, H. W, Zhoo, X. F. Jin, and Z. Q. Qiu. Phys. Kev. Lett. 93, JJ7205 (2thod)

${ }^{9} H$. J. Clroi, W. L. Ling, A. Scholl, J. H. Wotk, U. Bovensiepen, F. Tuyamis and Z. Q. Qiu, Plyys. Rev. B 66, 014409(2002).

${ }^{10} \mathrm{G}$. Meyer, T. Crecelius, A. Bawor, I. Mauch, and G. Kaind!,
Appl. Phys. Lett. 83, 1394 (2003).

"C. Won, Y. Z. Wu, J, Ghoi, W. Kim, A. Scholl, A. Doran, T. Owens, J. Wu, X. F. Jin, H. W. Zhoo, and Z. Q. Qiu, Phys. Rev. B $71,224429(2005)$

${ }^{12}$ M. Carubelli, O. V. Billoni, S. A. Pighin, S. A. Cannas, D. A. Stariolo, and F. A. Tantarit, Phys. Rev. B 77, 13441/7 (2008).

13. J. Gao, Y. Girard, V. Repain, A. Tejeda, R. Belkhou, N. Kongeinajile, C.. Chacon, G. Kodrry, and S. Roussite, Phys. Rey. В 77, 134429 (2008)

[4 3. P. Whilehead, A. B. Maclsaac, and K. De[Bell, P'hys. Rev, B 77. 174415 (2008).

${ }^{15}$ A. A. Macisasc, K. De'Bell, and J. P. Whilehtad, Phys. Rey. Lett. 80, 6]6 (1998).

${ }^{16}$ E. Y. Vednedenko, H. P. Oqnen, A. Ghazzli, J.-C. S. Lév'y, und J. Kirsiluner, Plyys. Rev. Lell. B4, 5884 (2000).

${ }^{17}$ A. P. Popov, N. V. \$korodumova, and O. Erikssion, Phys. Rev. B 
77,014415 (2008).

${ }^{18}$ J. Choi, J. Wu, C. Won, Y. Z Wu, A. Scholl, A. Doran, T. Owens, and Z. Q. Qiu, Phys. Rey. Lett. 98, 2t)7205 (2007).

${ }^{19}$ K. Mandal, S. P. Mandal, M. Vázquez, S. Puerta, and A. Hernando, Phys. Rev. B 65, 064402 (2002).

${ }^{20}$ Y, J. Jensen, K. H. Bennemaisn, P. Panlopoulos, M. Farle, Y. Wilhelm, andi K. Baberschke, Phys. Rey, B 60, R 14994 ( (1999)

2I S. S. P. Parkin, N. More, and K. P. Rodie, Ptyx. Rey. Lelt. 64, $2304(1990)$ )
${ }^{22}$ Z. Q. Qju, J. Pearkon, aind S. D. Bader, Phys. Rev. B 46, 8659 (I9y2).

${ }^{27}$ R. K. Kawakumi, E. Rotenbel'y, Ermesto I. Escorcia·Aparicio, Hyuk J. Choj, J. H. Wolfe. N. V. Smith, and Z. Q. Qiu, Phys. Rev. Lett. 82, 4098 (1999).

24 Ar, Abanov, W, Kalatsky, V. L. Pokrovsky, and W. M. Saslow, Phys. Rev. B 51, J023 (J995).

${ }^{25} \mathrm{Kwok}-\mathrm{O}$ m $\mathrm{Ng}$ and Dayid Vanderbill, Phyy. Rev. B 52, 2177 (1995). 


\section{DISCLAIMER}

This document was prepared as an account of work sponsored by the United States Government. While this document is belieyed to contain correct information, neither the United States Government nor any agency thereof, nor the Regents of the University of Californit, nor any of their employees, makes any warranty, express or implied, or assumes any legal responsibility for the accuracy, completeness, or usefulness of any information, apparapus, product, or process disclosed, of represents that its use would not infringe privately owned rights. Reference herein to any specific conmercial product, process, or service by its trade name, trademark, manufacturer, or otherwise, does not necessarily constitute or imply its endorsement, recommendation, or favoring by the United States Goverument of any agency thereof, or the Regents of the University of Califomia. The views and opinions of authors expressed herein do not necessarily state or reflect those of the United States Government or any agency thereof or the Regents of the University of California. 